NOTES AND CORRESPONDENCE

\title{
Interdecadal Variability of the Eastward Current in the South China Sea Associated with the Summer Asian Monsoon
}

\author{
GUIHUA WANG \\ State Key Laboratory of Satellite Ocean Environment Dynamics, SIO, SOA, Hangzhou, China \\ CHUNZAI WANG \\ Physical Oceanography Division, NOAA/Atlantic Oceanographic and Meteorological Laboratory, Miami, Florida \\ RUI XIN HUANG \\ Woods Hole Oceanographic Institution, Woods Hole, Massachusetts
}

(Manuscript received 30 December 2009, in final form 18 June 2010)

\begin{abstract}
Based on the Simple Ocean Data Assimilation (SODA) dataset and three types of Sverdrup streamfunction, an interdecadal variability of the eastward current in the middle South China Sea (SCS) during summer is identified. Both the pattern and strength of the summer Asian monsoon wind stress curl over the SCS contribute to the interdecadal variability of this current. From 1960 to 1979, the monsoon intensified and the zero wind stress curl line shifted southward. Both the core of positive wind stress curl in the northern SCS and the negative curl in the southern SCS moved southward and thus induced a southward shift of both the southern anticyclonic and northern cyclonic gyres, resulting in a southward displacement of the eastward current associated with these two gyres. In the meantime, the southern (northern) SCS anticyclonic (cyclonic) ocean gyre weakened (strengthened) and therefore also induced the southward shift of the eastward current near the intergyre boundary. In contrast, the eastward current shifted northward from 1980 to 1998 because the monsoon relaxed and the zero wind stress curl line shifted northward. After 1998, the eastward jet moved southward again as the zero wind stress curl line shifted southward and the SCS monsoon strengthened. The eastward current identified from the baroclinic streamfunction moved about $1.7^{\circ}$ more southward than that from the barotropic streamfunction, indicating that the meridional position of the eastward current is depth dependent.
\end{abstract}

\section{Introduction}

The South China Sea (SCS) is the largest semienclosed marginal sea in the tropical western Pacific. Its upperlayer circulation is driven mainly by the Asian monsoon. The monsoon-driven circulation shows a large seasonality, having a relatively short thermocline adjustment time of 1-4 months (Liu et al. 2001). Forced by the southwesterly monsoon wind in summer, the circulation in the basin consists of a cyclonic gyre north of about $12^{\circ} \mathrm{N}$

Corresponding author address: Guihua Wang, Second Institute of Oceanography, No. 36, Baochubei Road, Hangzhou, Zhejiang 310012, China.

E-mail: guihua_wanggh@yahoo.com.cn and a strong anticyclonic gyre south of $12^{\circ} \mathrm{N}$. Thus, there is an eastward current veering off central Vietnam between these two gyres (Liu et al. 2001). The large-scale cyclonic gyre in the northern SCS, the anticyclonic gyre in the southern SCS, and the accompanying eastward current between these two gyres are clearly evident in the summer mean thermocline depth characterized by $20^{\circ} \mathrm{C}$ isotherm (Fig. 1), which is derived from the Simple Ocean Data Assimilation (SODA) data (Carton and Giese 2008). Figure 2 also shows the vertical structure of the zonal current along $113^{\circ} \mathrm{E}$, derived from the SODA reanalysis data. Near the surface, the eastward current is confined within the latitude band between $9^{\circ}$ and $15^{\circ} \mathrm{N}$. At about $130 \mathrm{~m}$, the eastward current is present along $10^{\circ}-13^{\circ} \mathrm{N}$. Associated with the summer eastward jet, there is often 


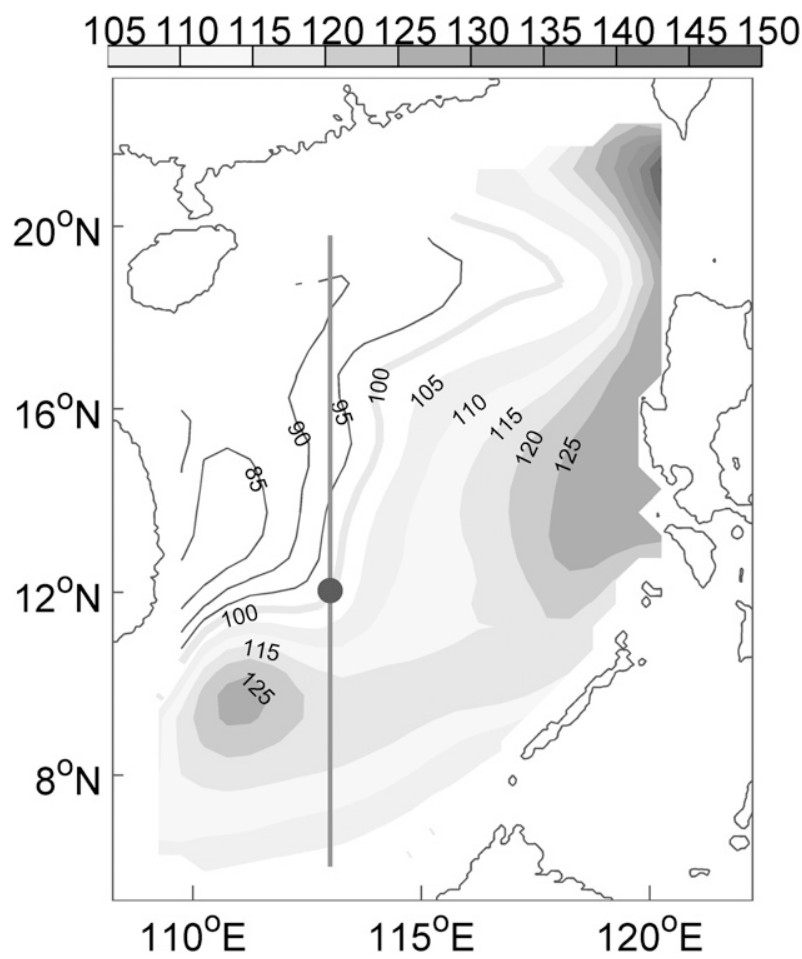

FIG. 1. Climatological summer mean isotherm depth $(\mathrm{m})$ of $20^{\circ} \mathrm{C}$ from SODA. Shaded values indicate the depth larger than $105 \mathrm{~m}$. The dot denotes the summer mean latitude of $T_{b}$ where the depth of $20^{\circ} \mathrm{C}$ is $100 \mathrm{~m}$ along the $113^{\circ} \mathrm{E}$ section.

a dipolelike eddy structure, consisting of an anticyclonic eddy south of the jet and a cyclonic eddy north of it (Metzger and Hurlburt 2001; Wang et al. 2006).

$\mathrm{Xu}$ et al. (1982) first identified the eastward jet from the climatologic map of dynamic height. In the past decade, the eastward jet was studied using different datasets, including satellite sea surface temperature, sea surface height, and chlorophyll signature (Kuo et al. 2000; Liu et al. 2002; Xie et al. 2003). The eastward jet is also found to exist from the surface to a depth of more than $400 \mathrm{~m}$ in temperature, salinity, and current profiler data (Fang et al. 2002). The eastward jet has a large seasonality: starting to appear in May or June, peaking in August or September, and disappearing in October (Metzger and Hurlburt 1996; Kuo et al. 2000; Xie et al. 2003; Wang et al. 2006). Because of advection by the eastward jet, the cold filament is located off central Vietnam and shows significant interannual variability. In 1998 when the 1997/98 El Niño was in the decay phase, the cold filament and midsummer cooling was weak, suggesting an interannual variability of the eastward jet (Wang 2004). As a major forcing of SCS circulation, the Asian monsoon contributes to the seasonal and interannual variability of the eastward jet (Xie et al. 2003; Wang 2004). The eastward jet is primarily governed by the

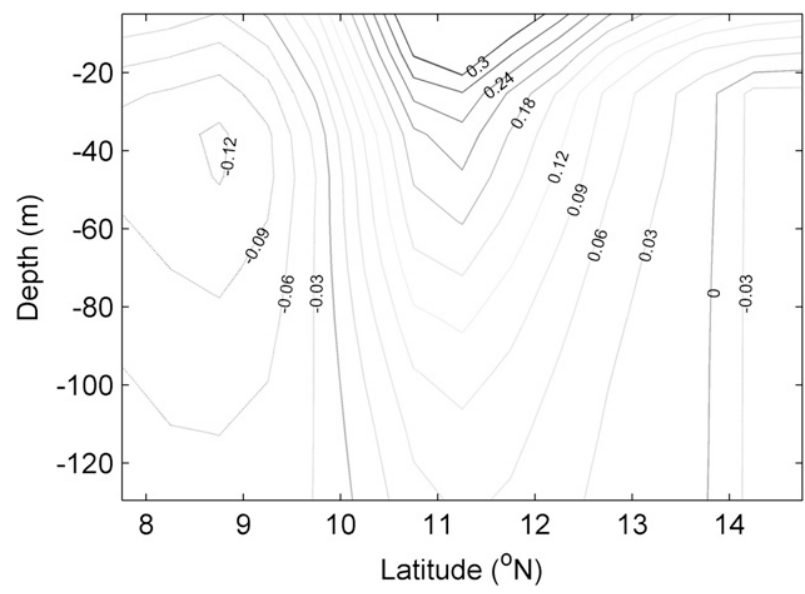

FIG. 2. Climatological summer mean zonal velocity $\left(\mathrm{m} \mathrm{s}^{-1}\right)$ across $7^{\circ}-15^{\circ} \mathrm{N}$ along $112.75^{\circ} \mathrm{E}$ taken from SODA. Positive values indicate eastward flow.

wind-driven circulation in the basin interior (Wang et al. 2006; Bayler and Liu 2008); in addition, it may be partly regulated by the coastal circulation (Gan and Qu 2008).

The Asian monsoon over the SCS (hereafter the SCS monsoon) also shows a strong interdecadal variability, which can be clearly seen in the distribution and strength of precipitation over east China, and the large-scale atmospheric circulation (Hu 1997). Wang et al. (2009) suggested that the interdecadal variability of the SCS summer monsoon is closely associated with ENSO. Before the late 1970s, the SCS summer monsoon was primarily influenced by the developing phase of ENSO, while after the late 1970s it was mainly influenced by the decaying phase of ENSO. Since the monsoon is a major forcing of SCS ocean circulation, a natural question is whether the oceanic eastward jet off central Vietnam in summer also varies on interdecadal time scale. This paper is focused on the eastward jet in the SCS, including its interdecadal variability and the causes.

\section{Simple diagnostic models}

Given the time-dependent wind stress in the basin, a barotropic streamfunction can be defined in terms of a time-delayed integral of the wind stress curl, as shown by Qiu and Lukas (1996), Liu et al. (2001), and Liu and Huang (2010, manuscript submitted to J. Phys. Oceanogr.):

$$
\begin{aligned}
\psi_{\mathrm{bt}}\left(x, y, t_{0}\right)= & -\frac{f}{\beta} \int_{x}^{x_{e}} w_{e}\left[x^{\prime}, y, t_{0}-\frac{x^{\prime}}{C(y)}\right] d x^{\prime} \\
& +\frac{1}{f \rho_{0}} \int_{x}^{x_{e}} \tau^{x} d x
\end{aligned}
$$

where $x$ and $y$ are the zonal and meridional coordinates, respectively; $t_{0}$ is a given time we chose; $f$ is the Coriolis 
parameter, $\beta$ is the meridional gradient of planetary vorticity; $x_{e}$ is the ocean eastern boundary; $w_{e}$ is the Ekman pumping velocity calculated from wind stress $w_{e}=$ $\partial / \partial x\left(\tau^{y} / \rho f\right)-\partial / \partial y\left(\tau^{x} / \rho f\right) ; \rho_{0}$ is the reference density of seawater, and $\tau^{x}$ and $\tau^{y}$ are the zonal and meridional components of the surface wind stress, respectively. In Eq. (1), $C(y)$ is the speed of long Rossby waves obtained by solving the linearized vertical eigenvalue problem with climatology temperature and salinity data (Cai et al. 2008), and $x^{\prime} / C(y)$ is the time delay due to the propagation of the Rossby wave.

The right-hand side of Eq. (1) consists of two terms: the Ekman pumping term and the term associated with the Ekman transport due to zonal wind stress. If both terms are included, then this streamfunction represents the timedependent barotropic transport streamfunction for flow integrated over the entire water column. Equation (1) is called the time-dependent barotropic Sverdrup balance.

If we omit the second term and consider the first term only, then Eq. (1) is reduced to

$$
\psi_{\mathrm{bc}}\left(x, y, t_{0}\right)=-\frac{f}{\beta} \int_{x}^{x_{e}} w_{e}\left[x^{\prime}, y, t_{0}-\frac{x^{\prime}}{C(y)}\right] d x^{\prime} .
$$

Equation (2) is called the time-dependent upper-ocean baroclinic Sverdrup balance and the streamfunction is called the time-dependent baroclinic streamfunction. Note that "baroclinic" used here means the circulation below the Ekman layer; thus, it is different from the traditional definition. In fact, this baroclinic streamfunction represents the geostrophic flow below the Ekman layer.

If we omit the delay time correction in the first term of Eq. (1) and assume that the ocean is in near equilibrium with the wind forcing, then Eq. (1) is reduced to the following form:

$\psi_{\mathrm{bt}}^{\text {no delay }}\left(x, y, t_{0}\right)=-\frac{f}{\beta} \int_{x}^{x_{e}} w_{e}\left(x^{\prime}, y, t_{0}\right) d x^{\prime}+\frac{1}{f \rho_{0}} \int_{x}^{x_{e}} \tau^{x} d x$.
This streamfunction without considering the effect of the time-delayed Rossby wave is called the time-independent barotropic streamfunction, and the corresponding transport is called the time-independent barotropic transport.

\section{Data and SCS monsoon indices}

The wind data are the recent updated data provided by the 40-yr European Centre for Medium-Range Weather Forecasts Re-Analysis (ERA-40) spanning the period from 1958 to 2008. The wind field is used to calculate the time evolution of the streamfunction defined in Eqs. (1)(3), and maps of the summer-season circulation are shown in Figs. 3b and 4. The wind data were also used in generating the SODA reanalysis product through the Parallel Ocean Program (Carton and Giese 2008).

Large-scale circulation in the upper ocean of the SCS is dominated by wind forcing. The essential part of the SCS monsoon wind variability can be represented in terms of its vorticity. As Wang et al. (2009) showed, the meridional gradient of zonal wind can be used as a good measure for SCS monsoon variations from intraseasonal to interdecadal time scales. They proposed an SCS monsoon index (SCSMI), which is defined as the zonal wind difference between a north box and a south box over the SCS at $850 \mathrm{hPa}$. Because the upper-level circulation in the SCS is primarily regulated by wind stress curl, which can be further reduced to an index related to the meridional gradient of zonal wind stress, we introduce a modified SCSMI:

$$
\begin{aligned}
\operatorname{SCSMI}= & \tau^{x}\left(5.25^{\circ}-10.25^{\circ} \mathrm{N}, 110^{\circ}-120^{\circ} \mathrm{E}\right) \\
& -\tau^{x}\left(17.25^{\circ}-22.25^{\circ} \mathrm{N}, 110^{\circ}-120^{\circ} \mathrm{E}\right),
\end{aligned}
$$

where $\tau^{x}$ is the surface zonal wind stress. For a better understanding of the physics in Eq. (4), we rearrange Eq. (4) as follows:

$$
\begin{aligned}
\operatorname{SCSMI}= & {\left[\tau^{x}\left(5.25^{\circ}-10.25^{\circ} \mathrm{N}, 110^{\circ}-120^{\circ} \mathrm{E}\right)-\tau^{x}\left(\text { around } 12^{\circ} \mathrm{N}, 110^{\circ}-120^{\circ} \mathrm{E}\right)\right] } \\
& +\left[\tau^{x}\left(\text { around } 12^{\circ} \mathrm{N}, 110^{\circ}-120^{\circ} \mathrm{E}\right)-\tau^{x}\left(17.25^{\circ}-22.25^{\circ} \mathrm{N}, 110^{\circ} \mathrm{E}-20^{\circ} \mathrm{E}\right)\right] .
\end{aligned}
$$

Now the physics is clear: the first and second square brackets represent the wind stress curl in the southern and northern SCSs, respectively. If the wind stress curl in the southern SCS is smaller (more negative) and/or the wind stress curl in the northern SCS is smaller (less positive), then the SCSMI is smaller. The corresponding changes in the ocean include strengthening of the southern SCS anticyclonic gyre and weakening of the northern SCS cyclonic gyre, and thus a northward shift of the eastward current between these two gyres. On the other hand, if the wind stress curl in the southern SCS is larger (less negative) and/or the wind stress curl in the northern SCS is larger (more positive), then the SCSMI is larger, the southern SCS anticyclonic circulation is weakened and/or the northern SCS cyclonic circulation is strengthened, and thus the eastward current between these two gyres moves southward. The SCSMI proposed above can serve as 

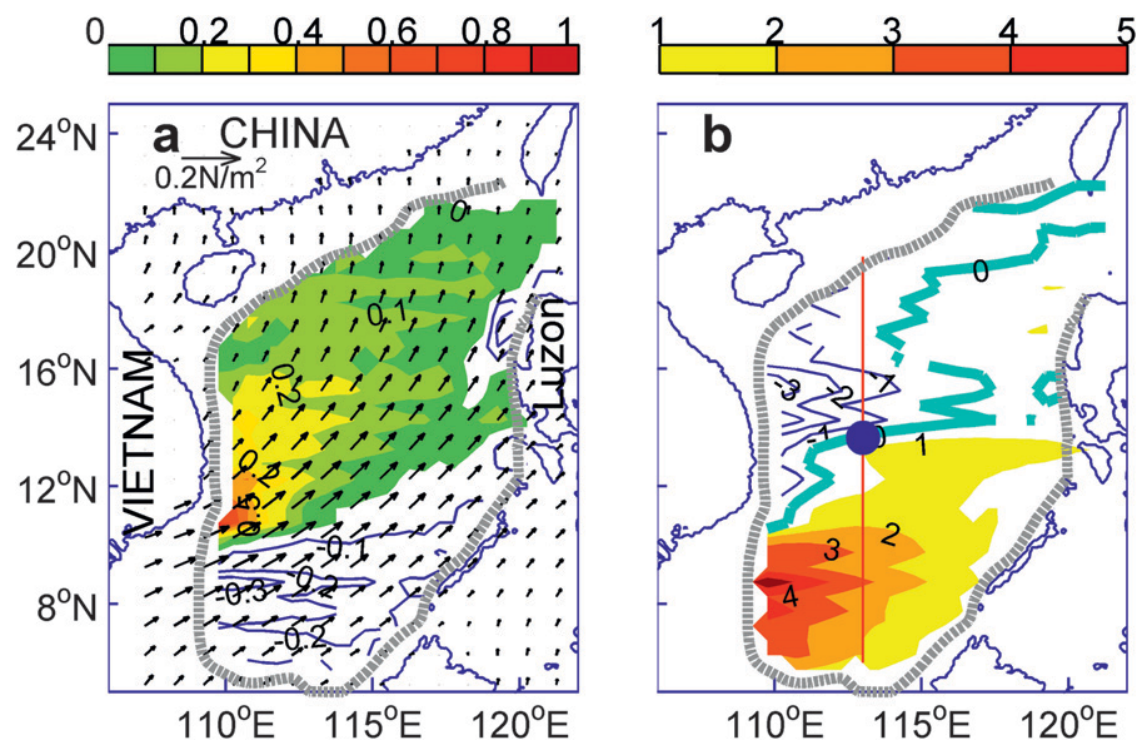

FIG. 3. (a) Summer mean ERA-40 wind stress (vectors, $\mathrm{N} \mathrm{m}^{-2}$ ) and wind stress curl (contours, $10^{-6} \mathrm{~N} \mathrm{~m}^{-3}$ ). The dot denotes the latitude of summer mean zero wind stress curl line. (b) Summer mean Sverdrup transport $\left(1 \mathrm{~Sv} \equiv 10^{6} \mathrm{~m}^{3} \mathrm{~s}^{-1}\right)$ derived from TIBT. The cyan line in (b) is the position for the eastward current derived from the model. The dot denotes $\mathrm{Y}_{\mathrm{b}}$ of eastward current in the summer mean streamfunction. In (a) and (b), the positive values are shaded and negative values are contoured. The thick dashed line is for the $200-\mathrm{m}$ isobaths.

a good index for the wind-driven SCS ocean circulation and the north-south shift of the eastward current. Although the index is slightly different from that defined by Wang et al. (2009), the variability of the two indices is similar.

\section{Results}

a. Wind forcing and eastward current

The SCS southwesterly monsoon usually starts in April or May. It is further developed from June to August and

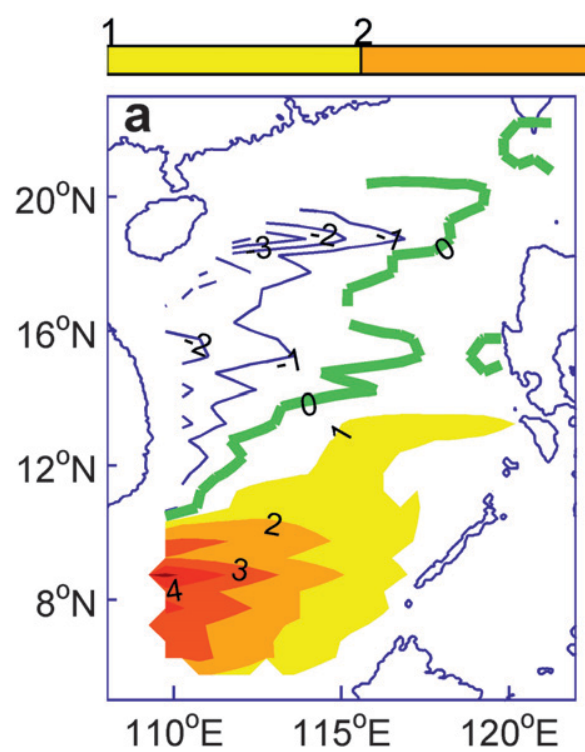

$3 \quad 4$
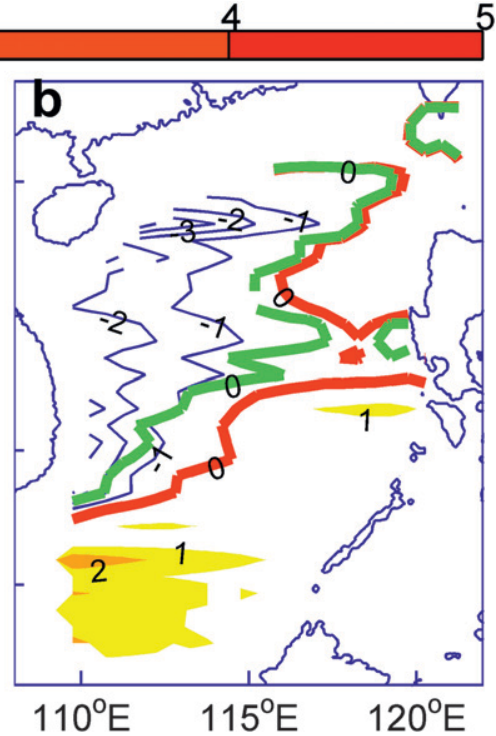

FIG. 4. (a) Summer mean Sverdrup streamfunction (Sv) derived from TDBT. (b) As in (a), but derived from TDBC. The green lines in (a) and (b) are for the position of the eastward current derived from TDBT. The red line in (b) is for the position of the eastward current derived from the TDBC. The positive (negative) values are shaded (contoured). 


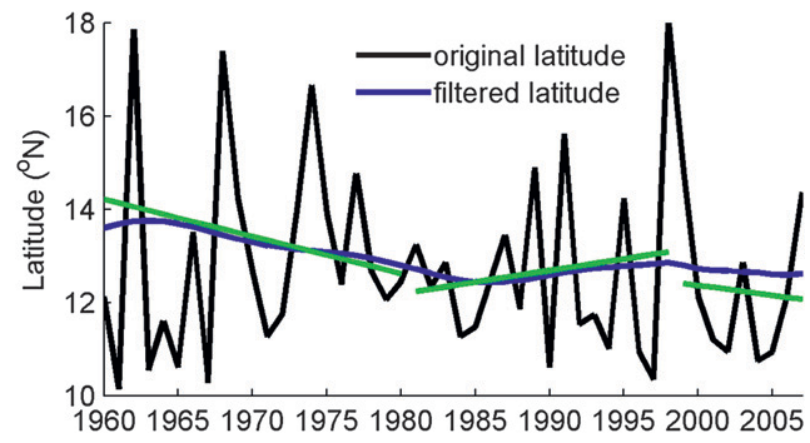

FIG. 5. Time series of the eastward current latitude derived from SODA. The black line is the original latitude of the eastward current from SODA data; the blue line is the latitude with the 15-yr low-passed Butterworth filter. The straight green lines are the fit lines for the three time periods 1960-79, 1980-98, and 1999-2007.

retreats in September. Associated with this wind distribution, the summer wind stress curl is positive in the northwestern SCS and negative in the southeastern SCS during the summer months (Fig. 3a). Driven by the wind stress curl, a double gyre circulation, with a cyclonic gyre north of about $12^{\circ} \mathrm{N}$ and an anticyclonic gyre south of $12^{\circ} \mathrm{N}$, starts to develop from May (Wang et al. 2006). The double gyres are further developed in June and July, and mature in August. The oceanic eastward jet between these two gyres also intensifies as summer progresses. Figure $3 \mathrm{~b}$ demonstrates the summer mean wind-driven Sverdrup ocean circulation, by assuming that the ocean is in near equilibrium with monthly monsoon forcing.

A more accurate streamfunction in the SCS, the linear time-dependent Sverdrup theory [Eq. (1)], can be used to include the effect of thermocline adjustment for the time-dependent wind stress. With speed on the order of $10-40 \mathrm{~cm} \mathrm{~s}^{-1}$, the planetary waves cross the SCS in 1-5 months (Cai et al. 2008). Figure 4 a shows the summer mean streamfunction including the thermocline adjustment. Although transportation patterns shown in Figs. 4a and $4 \mathrm{~b}$ share similar features, the difference in magnitude in the northern SCS is prominent. The cyclonic gyre in Fig. 4a weakens from $13^{\circ}$ to $16^{\circ} \mathrm{N}$, while it intensifies north of $16^{\circ} \mathrm{N}$. Such a difference may result from the wind stress curls (positive wind stress curl northwestern Luzon Island and negative wind stress curl west of Manila Bay) in the northeasterly winter monsoon season (Wang et al. 2008). The comparison between these two solutions demonstrates that the winter wind can affect the summer circulation in the northern SCS. The difference in magnitude south of $13^{\circ} \mathrm{N}$ is relatively small because the thermocline adjustment time at this latitude is about one month and thus the ocean is nearly in equilibrium with the monthly wind forcing. It is interesting to note that the positions of the eastward flow in Figs. 3b and 4a, as identified by the zero streamfunction contours, are almost identical.
TABLE 1. The trend rates in the three periods for the SCSMI, the position of $\mathrm{W}_{\mathrm{b}}$, the position of $\mathrm{T}_{\mathrm{b}}$ from the SODA dataset, and the position of $\mathrm{Y}_{\mathrm{b}}$ derived from three types of Sverdrup streamfunction: TIBT, TDBT, and TDBC. The units for the SCSMI, $\mathrm{W}_{\mathrm{b}}$, and $\mathrm{Y}_{\mathrm{b}}$ are $\mathrm{N} \mathrm{m}^{-2} \mathrm{yr}^{-1},{ }^{\circ} \mathrm{N} \mathrm{yr}^{-1}$, and ${ }^{\circ} \mathrm{N} \mathrm{yr}^{-1}$, respectively.

\begin{tabular}{lccc}
\hline \hline Models & $1960-79$ & $1979-98$ & $1998-2008$ \\
\hline SODA & -0.080 & 0.062 & -0.050 \\
TIBT & -0.074 & 0.164 & -0.460 \\
TDBT & -0.125 & 0.191 & -0.338 \\
TDBC & -0.175 & 0.212 & -0.503 \\
W $_{\text {B }}$ & -0.0288 & 0.0795 & -0.2925 \\
SCSMI & 0.0011 & -0.0008 & 0.0052 \\
\hline
\end{tabular}

To examine the effect of Ekman transport on the latitudinal position of the eastward flow, Fig. $4 \mathrm{~b}$ shows the upper-ocean baroclinic streamfunction. Although the pattern and magnitude of baroclinic streamfunction is similar to those of the barotropic streamfunction in Fig. 3a, the latitude of the eastward flow is significantly alternated by including the Ekman transport. The eastward flow in baroclinic streamfunction (red line in Fig. 4b) is about $1^{\circ}-3^{\circ}$ more southward than that obtained from the barotropic streamfunction (green line in Figs. $4 \mathrm{a}$ and $4 \mathrm{~b}$ ). This indicates that the eastward current is depth dependent.

Comparing these three types of theoretic Sverdrup streamfunction (Figs. 3b, 4a, and 4b) with the SODA reanalysis (Fig. 1) suggests that the Sverdrup balance proves to be a good representation of the oceanic transport pattern in the SCS. Thus, it is possible to use the Sverdrup theory to examine the SCS circulation in the summer season and infer the corresponding variability of the eastward current.

\section{b. Interdecadal variability of the eastward current}

Now we focus on the north-south migration of the eastward jet. We define $T_{b}$ as the latitude where the depth of $20^{\circ} \mathrm{C}$ is $100 \mathrm{~m}$ along the $113^{\circ} \mathrm{E}$ section, as inferred from the SODA data. The solid dot in Fig. 1 denotes the mean position of $T_{b}$ in summer. Figure 5 shows the time series of $\mathrm{T}_{\mathrm{b}}$ from the SODA data during 1960-2007. It is clear that the time series contains interdecadal signals. Before 1980, the eastward current gradually shifted to the south with time, from $18.0^{\circ} \mathrm{N}$ around 1962 to $12.2^{\circ} \mathrm{N}$ around 1979 . After 1980, the eastward current showed a northward shift with time, reaching the northernmost position (around $18.0^{\circ} \mathrm{N}$ ) in 1998 . The eastward jet then moved southward again after 1998. Figure 5 also shows the results obtained by a 15 -yr low-pass Butterwort filter, which can separate the interdecadal signals from other unwanted signals. The low-pass-filtered results also show that the eastward jet moved southward, northward, and southward during the periods 1960-79, 1980-98, and 1999-2007, respectively. The trend rates in the three periods are listed in Table 1. 

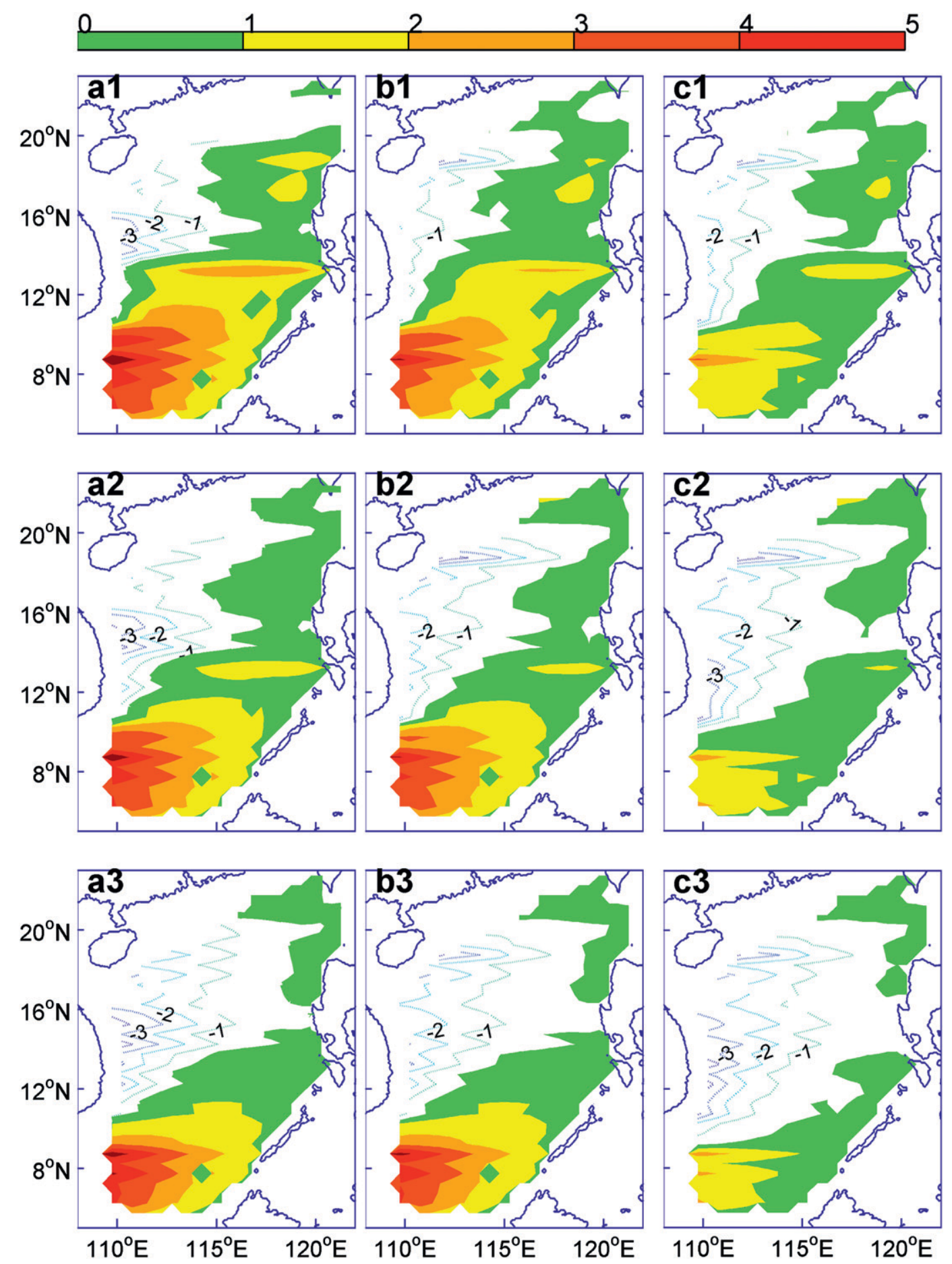

FIG. 6. (a1)-(a3) Summer mean Sverdrup transport (Sv) derived from TIBT over the periods 1960-79, 1980-98, and 1999-2008, respectively; (b1)-(b3) as in (a1)-(a3) but for TBDT; (c1)-(c3) are for TDBC.

The three types of Sverdrup model can be used to study the interdecadal variability of the eastward currents, and Fig. 6 shows the summer ensemble mean streamfunction derived from the three models over the periods 1960-79, 1980-98, and 1998-2007. The patterns of these three types of streamfunction for each period are very similar, except the eastward current over the years 1960-79 is slightly more northward than the other two periods. Therefore, these three types of Sverdrup balance model can be used as useful diagnosis tools. Actually, the pattern 

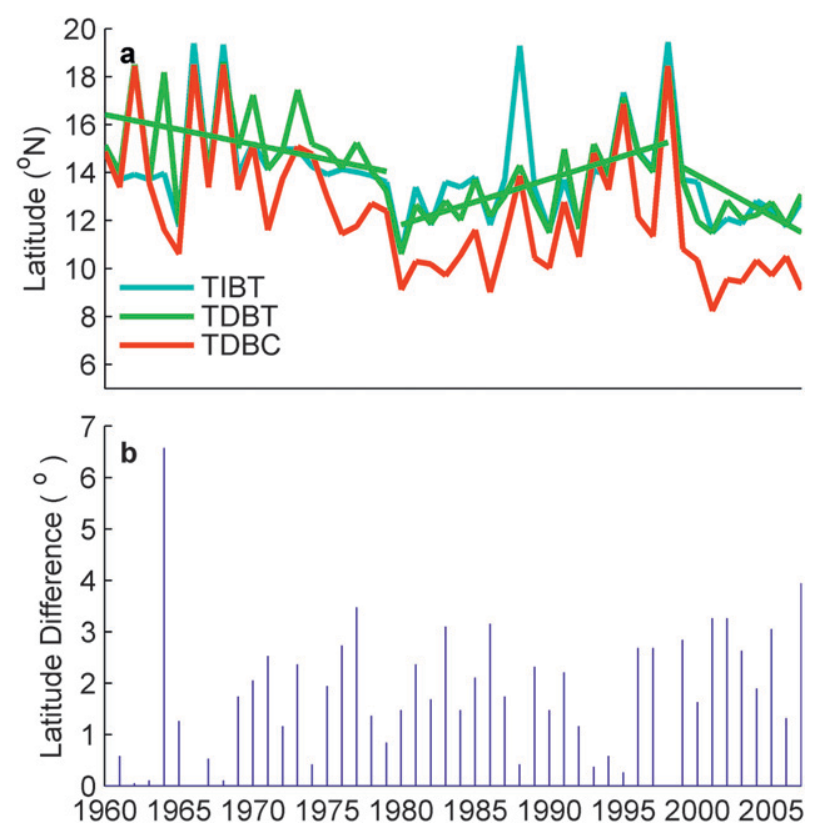

FIG. 7. (a) Time series of the eastward current latitude derived from TIBT, TDBT, and TDBC. The green straight lines are the fit lines in the three periods for TDBT. (b) The difference between TDBT and TDBC (TDBT minus TDBC). The positive value denotes that TDBT is more northward than TDBC.

of these streamfunctions is relative stable, because the wind stress curl pattern is strongly regulated by flow over steep topography associated with the mountain on the east coast of Vietnam (Xie et al. 2003).

As the next step, these three types of Sverdrup streamfunction were used to examine the interdecadal variability of the eastward current. We define $Y_{b}$ as the latitude where the time-independent barotropic streamfunction is zero along the $113^{\circ} \mathrm{E}$ section. The solid dot in Fig. $3 b$ denotes the mean position of $\mathrm{Y}_{\mathrm{b}}\left(13.76^{\circ} \mathrm{N}\right)$ in summer by assuming that the ocean is in near equilibrium with monthly monsoon forcing. For the cases shown in Figs. $4 \mathrm{a}$ and $4 \mathrm{~b}$, the eastward currents are located at $13.74^{\circ}$ and $11.84^{\circ} \mathrm{N}$ for the time-dependent mean barotropic and baroclinic streamfunctions, respectively.

Figure 7a shows three time series of $Y_{b}$ from the timeindependent barotropic Sverdrup model (TIBT), the time-dependent barotropic Sverdrup model (TDBT), and the time-dependent baroclinic Sverdrup model (TDBC) during 1960-2007. Generally, these three time series have good correlation with the time series of $T_{b}$ from the SODA data. The correlation coefficients are $0.48,0.56$, and 0.52 between $T_{b}$ and $Y_{b}$ derived from the time-independent barotropic Sverdrup model, the timedependent barotropic Sverdrup model, and the timedependent baroclinic Sverdrup model, respectively. All of them are significant at the $95 \%$ confidence level. These three time series also include noticeable interdecadal signals. Before 1980, the eastward current shifted to the south with time, from $16.5^{\circ} \mathrm{N}$ around 1965 to $11^{\circ} \mathrm{N}$ around 1979. After 1980, the eastward current moved northward with time, reaching the northernmost position in 1998. The eastward jet then moved southward again after 1998. The trend rates in the three periods for the three time series are listed in Table 1. All the trends in Table 1 are statistically significant at the $95 \%$ level. The trend rates for the time-dependent baroclinic Sverdrup model, regardless of upward or downward, are larger than those for the time-dependent barotropic Sverdrup model.

The time series of $Y_{b}$ of the eastward flow derived from the time-independent barotropic Sverdrup model and the time-dependent barotropic Sverdrup model are almost the same (Fig. 7a). Both the time series (Fig. 7a) and the spatial patterns (Figs. 3b and 4a) demonstrate that the winter wind may not affect the eastward current position in summer, while it can affect the northern SCS circulation in summer. Again, the time series of $Y_{b}$ for the eastward flow derived from the time-dependent baroclinic Sverdrup model shows that latitude $Y_{\mathrm{b}}$ is strongly affected by Ekman transport and located about $0^{\circ}-6.6^{\circ}$ (mean value is $1.7^{\circ}$ ) farther southward than that obtained from the barotropic streamfunction. Again, this indicates that the latitudinal position of the eastward current is depth dependent. The largest difference is $6.6^{\circ} \mathrm{N}$ in 1964 , while there is no difference in 1966 and 1999 (Fig. 7b).

\section{c. Mechanism of the interdecadal variability of eastward current}

To understand the mechanism that determines the interdecadal variability of the latitude $Y_{b}$ of the eastward current, we first look at the pattern of positive wind stress curl in the northwestern SCS and negative wind stress curl in the southeastern SCS in summer. To simply represent the pattern of summer wind stress curl in the SCS, we introduce another index, the latitude $\mathrm{W}_{\mathrm{b}}$, where the wind stress curl is zero along $113^{\circ} \mathrm{E}$. Figure 8a shows the time series of the latitude $\mathrm{W}_{\mathrm{b}}$ derived from the summer wind stress curl for the period 1960-2007. In general, the interdecadal signal and north-south shift of the zero wind stress curl line are similar to those of the eastward current. Before $1980, \mathrm{~W}_{\mathrm{b}}$ shifted to the south with time, from $13.5^{\circ} \mathrm{N}$ around 1965 to $9.3^{\circ} \mathrm{N}$ around 1979 ; this indicates that the region of positive wind stress curl in the northern SCS and that of negative wind stress curl in the southern SCS were located more southward. Thus, the anomalous wind stress curls induced a southward migration of the northern cyclonic gyre and southern anticyclonic gyre. As a result, the eastward current associated with the two gyres moved southward. During 1980-98, $\mathrm{W}_{\mathrm{b}}$ moved northward and reached the northernmost position in 1998; 

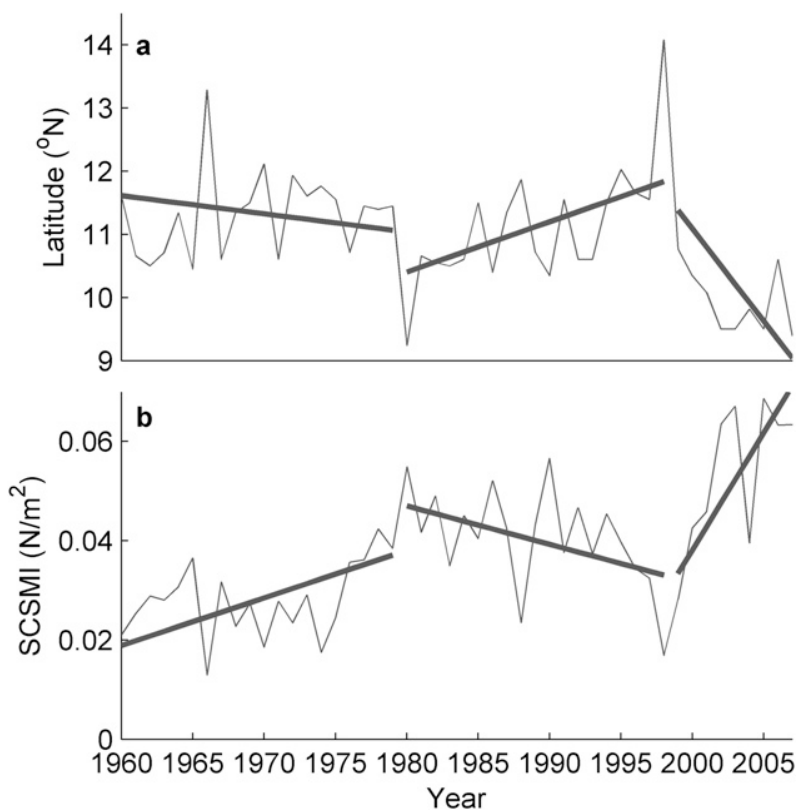

FIG. 8. (a) Time series of $\mathrm{W}_{\mathrm{b}}$. (b) The SCSMI during summer. The straight lines are the fit lines in the three periods.

the eastward current shifted to the north correspondingly. After 1998, the eastward current moved to the south again with the southward shift of $\mathrm{W}_{\mathrm{b}}$. The trend rates of $\mathrm{W}_{\mathrm{b}}$ in the three periods are also listed in Table 1.

As described in section 3, to further investigate the mechanism of the interdecadal variability of the latitude $\mathrm{Y}_{\mathrm{b}}$ of the eastward current, we also calculated the SCSMI, and the time series of the SCSMI is shown in Fig. 8b. The interdecadal signals of the SCSMI are consistent with that of $Y_{b}$. From 1965 to 1980, the SCSMI increased from 0.02 to $0.06 \mathrm{~N} \mathrm{~m}^{-2}$. After 1980, the index first declined and then increased again after 1998. The trend rates of the SCSMI in these three periods are listed in Table 1. The correlation coefficients between the SCSMI and $\mathrm{Y}_{\mathrm{b}}$ of the three time series from the time-independent barotropic Sverdrup model, the time-dependent barotropic Sverdrup model, and the time-dependent baroclinic Sverdrup model are $-0.69,-0.70$, and -0.72 , respectively-all of them are significant at the $95 \%$ confidence level. The good correlation indicates the shift of the eastward current is strongly linked to the monsoon. When the SCSMI is strong (weak), the eastward flow is shifted southward (northward).

Therefore, the dynamic linkage between the SCS monsoon and the north-south position of the eastward current on interdecadal scale can be described as follows. Before 1980, the strengthening of the SCS monsoon gave rise to a weakened wind stress curl in the southern SCS and/or a strengthened wind stress curl in the northern SCS. The weakened (strengthened) wind stress curls imply a subdued (amplified) ocean gyre in the southern (northern)
SCS, and the eastward jet between the two gyres moves southward through nonlinear processes (Wang et al. 2006). During 1980-98, the monsoon index decreased, the anticyclonic gyre in the southern SCS intensified, and/or the cyclonic gyre in the northern SCS weakened; therefore, the eastward jet moved northward. After 1998, the eastward jet moved southward again as the monsoon index was increased.

\section{Summary and conclusions}

In summer, SCS ocean circulation consists of a cyclonic gyre north of about $12^{\circ} \mathrm{N}$ and an anticyclonic gyre south of $12^{\circ} \mathrm{N}$. Between these two gyres, there is an eastward current veering off central Vietnam. To the best of our knowledge, the interdecadal variability of the eastward current has not been examined. Our results show that the eastward jet moved southward, northward, and southward during the periods 1960-79, 1980-98, and 19992007, respectively.

We hypothesize that the interdecadal variability of the eastward current is strongly associated with the monsoon wind, which also shows interdecadal signals in wind stress curl pattern and wind stress strength. First, the interdecadal shift of the zero wind stress curl line in the SCS is directly linked to the shift of the eastward current. In fact, the variations in wind stress curl change the position of the southern anticyclonic ocean gyre and northern cyclonic ocean gyre, inducing the shift of the eastward current between the two ocean gyres. Second, the competition of positive wind stress curl in the northern SCS and negative wind stress curl in the southern SCS is also an important source of interdecadal variability. As the SCS monsoon increased (decreased) during the periods 1960-79 and 1999-2007 (1980-98), the anticyclonic gyre in the southern SCS weakened (strengthened) and the cyclonic gyre in the northern SCS were strengthened (weakened), and thus they induced the southward (northward) migration of the eastward jet through nonlinear processes.

Our results also indicate that the eastward current in baroclinic streamfunction is located about $0^{\circ}-6.6^{\circ}$ (mean value is $1.7^{\circ}$ ) farther southward than that from the barotropic streamfunction, suggesting that the meridional shift of the eastward current is depth dependent.

The SCS monsoon has a robust interdecadal variability, but the mechanisms for the interdecadal monsoon change remains to be explained (Wang et al. 2009). The present work shows the interdecadal variability of the monsoon is a major cause of the interdecadal variability of the eastward jet in the SCS. However, the influence of the interdecadal variability of the eastward jet on the SCS sea surface temperature and chlorophyll signature remains a challenging issue. 
Acknowledgments. This study was supported by the National Basic Research Program (Grant 2007CB816003) and the National Natural Science Foundation of China (Grants 40976017, 40730843, and 40876004). We also thank Dr. Cai Shuqun, who kindly provided the code for calculating the Rossby wave speed; and Mr. Ling Zheng, who helped prepare the manuscript. Helpful comments from the three anonymous reviewers are greatly appreciated.

\section{REFERENCES}

Bayler, E. J., and Z. Liu, 2008: Basin-scale wind-forced dynamics of the seasonal southern South China Sea gyre. J. Geophys. Res., 113, C07014, doi:10.1029/2007JC004519.

Cai, S. Q., X. M. Long, R. H. Wu, and S. G. Wang, 2008: Geographical and monthly variability of the first baroclinic Rossby radius of deformation in the South China Sea. J. Mar. Syst., 74, $711-720$.

Carton, J. A., and B. S. Giese, 2008: A reanalysis of ocean climate using Simple Ocean Data Assimilation (SODA). Mon. Wea. Rev., 136, 2999-3017.

Fang, W., G. Fang, P. Shi, Q. Huang, and Q. Xie, 2002: Seasonal structures of upper layer circulation in the southern South China Sea from in situ observations. J. Geophys. Res., 107, 3202, doi:10.1029/2002JC001343.

Gan, J., and T. Qu, 2008: Coastal jet separation and associated flow variability in the southwest South China Sea. Deep-Sea Res. I, 55, 1-19.

Hu, Z. Z., 1997: Interdecadal variability of summer climate over East Asia and its association with 500 hpa height and global sea surface temperature. J. Geophys. Res., 102,19 403-19 412.

Kuo, N.-J., Q. Zheng, and C.-R. Ho, 2000: Satellite observation of upwelling along the western coast of the South China Sea. Remote Sens. Environ., 74, 463-470.
Liu, K.-K., S.-Y. Chao, P.-T. Shaw, G.-C. Gong, C.-C. Chen, and T. Y. Tang, 2002: Monsoon-forced chlorophyll distribution and primary production in the South China Sea: Observations and a numerical study. Deep-Sea Res. I, 49, 1387-1412.

Liu, Z., H. Yang, and Q. Liu, 2001: Regional dynamics of seasonal variability in the South China Sea. J. Phys. Oceanogr., 31, 272-284.

Metzger, E. J., and H. Hurlburt, 1996: Coupled dynamics of the South China Sea, the Sulu Sea, and the Pacific Ocean. J. Geophys. Res., 101, 12 331-12 352.

— and - 2001: The nondeterministic nature of Kuroshio penetration and eddy shedding in the South China Sea. J. Phys. Oceanogr., 31, 1712-1732.

Qiu, B., and R. Lukas, 1996: Seasonal and interannual variability of the North Equatorial Current, the Mindanao Current and the Kuroshio along the Pacific western boundary. J. Geophys. Res., 101, 12 315-12 330

Wang, B., F. Huang, Z. Wu, J. Yang, X. Fu, and K. Kikuchi, 2009: Multi-scale climate variability of the South China Sea monsoon: A review. Dyn. Atmos. Oceans, 47, 15-37.

Wang, G., 2004: Discussion on the movement of mesoscale eddies in the South China Sea (in Chinese). Ph.D. dissertation, College of Physical and Environmental Oceanography, Ocean University of China, $96 \mathrm{pp}$.

- D. Chen, and J. Su, 2006: Generation and life cycle of the dipole in South China Sea summer circulation. J. Geophys. Res., 111, C06002, doi:10.1029/2005JC003314.

— — - and _ 2008: Winter eddy genesis in the eastern South China Sea due to orographic wind jets. J. Phys. Oceanogr., 38, 726-732.

Xie, S.-P., Q. Xie, D. Wang, and W. T. Liu, 2003: Summer upwelling in the South China Sea and its role in regional climate variations. J. Geophys. Res., 108, 3261, doi:10.1029/2003JC001867.

Xu, X. Z., Z. Qiu, and H. C. Chen, 1982: The general descriptions of the horizontal circulation in the South China Sea. Proceedings of the 1980 Symposium on Hydrometeorology of the Chinese Society of Oceanology and Limnology, Science Press, 137-145. 